\title{
Modeling temperature and moisture dependent emissions of carbon dioxide and methane from drying dairy cow manure
}

\author{
Enzhu HU ${ }^{1,2}$, Pakorn SUTITARNNONTR ${ }^{2}$, Markus TULLER ${ }^{3}$, Scott B. JONES (凶) ${ }^{2}$ \\ 1 Institute of Resources and Environmental Sciences, School of Metallurgy, Northeastern University, Shenyang 110819, China \\ 2 Department of Plants, Soils and Climate, Utah State University, Logan, UT 84322, USA \\ 3 Department of Soil, Water and Environmental Science, The University of Arizona, Tucson, AZ 85721, USA
}

\begin{abstract}
Greenhouse gas emissions due to biological degradation processes of animal wastes are significant sources of air pollution from agricultural areas. The major environmental controls on these microbe-induced gas fluxes are temperature and moisture content. The objective of this study was to model the effects of temperature and moisture content on emissions of $\mathrm{CO}_{2}$ and $\mathrm{CH}_{4}$ during the ambient drying process of dairy manure under controlled conditions. Gas emissions were continuously recorded over $15 \mathrm{~d}$ with paired fully automated closed dynamic chambers coupled with a Fourier Transformed Infrared gas analyzer. Water content and temperature were measured and monitored with capacitance sensors. In addition, on days $0,3,6,9,12$ and $15, \mathrm{pH}$, moisture content, dissolved organic carbon and total carbon (TC) were determined. An empirical model derived from the Arrhenius equation confirmed high dependency of carbon emissions on temperature and moisture content. Results indicate that for the investigated dairy manure, $6.83 \%$ of $\mathrm{TC}$ was lost in the form of $\mathrm{CO}_{2}$ and $0.047 \%$ of $\mathrm{TC}$ was emitted as $\mathrm{CH}_{4}$. Neglecting the effect of temperature, the moisture contents associated with maximum gas emissions were estimated as 0.75 and $0.79 \mathrm{~g} \cdot \mathrm{g}^{-1}$ for $\mathrm{CO}_{2}$ and $\mathrm{CH}_{4}$, respectively.
\end{abstract}

Keywords carbon dioxide, dairy manure, methane, moisture, temperature

\section{Introduction}

Annually in the USA, over 9 million dairy cows generate an estimated 226 billion $\mathrm{kg}$ of wet manure ${ }^{[1]}$. Animal manure and its common use as fertilizer contribute to gaseous emissions, significantly degrading air quality to the detriment of human health and the environment ${ }^{[2-4]}$.

Received September 21, 2017; accepted December 3, 2017

Correspondence: scott.jones@usu.edu
The challenge in assessing emission rates is complicated by the various factors affecting emissions, including type and number of animals, nutrient inputs and feeding operations, confinement conditions, manure management practices, and environmental conditions ${ }^{[5]}$. Temperature and moisture content are the primary environmental variables influencing gas emission rates, through their influence on metabolic activity of microorganisms, manure gas diffusion, nutrient availability and redistribution ${ }^{[6]}$.

Once manure is excreted, processes of biological decomposition and formation of gaseous compounds continue. The peak emissions occur shortly after deposition and diminish significantly within a few days as manure dries ${ }^{[7]}$. During this process, various chemical, rheological and structural changes take place inside manure piles. The organic matter is decomposed by microorganisms and enzymes under anaerobic and/or aerobic conditions, and the end products of $\mathrm{CO}_{2}, \mathrm{CH}_{4}$ and some other gases, diffuse through the manure surface crust.

Temperature and moisture content significantly impact microbial activity and gas diffusion processes driving emissions from farmyard manure and manure compost ${ }^{[8-10]}$. For example, methanogenesis in solid manure increased with increasing temperature ${ }^{[11]}$. Greater moisture content induces three kinds of microbial metabolism: inactive, aerobic and fermentative at low, moderate and high moisture contents, respectively, and hence influences gas emission rates ${ }^{[12]}$. Relatively high moisture content promotes $\mathrm{CH}_{4}$ and $\mathrm{N}_{2} \mathrm{O}$ emissions from composting dairy manure because of the acceleration of anaerobic conditions arising from reduced oxygen supply inside compost piles ${ }^{[13]}$. The reduced oxygen supply is generally limited by low gas diffusion into or out of porous media when the amount of air-filled pore space is below the gas percolation threshold occurring at high moisture levels ${ }^{[14]}$. As manure dries, an increase in those anaerobically generated gasses is accompanied by an increase in the number of air-filled pores beyond the gas percolation 
threshold. This results in a commensurate increase in oxygen supply into the manure resulting in a transition from anaerobic to aerobic activity. This optimal aerobic wet condition leads to maximum generation and emission of microbial generated gasses. Continued drying of manure decreases water availability to microbes and diminished water pathways for transport of nutrients, resulting in reduced microbial activity ${ }^{[15]}$. In-depth quantitative knowledge about temperature and moisture effects on gas emission rates from dairy manure is still limited. Growing interest in potential sources and mitigation of greenhouse gas emissions motivates interest in understanding and predicting the simultaneous organic matter degradation, moisture content decline and biogas diffusion during the ambient drying process of dairy manure. Recent work in this regard includes characterization of dairy cow manure with respect to the hydraulic and thermal properties needed for modeling of these complex processes ${ }^{[16]}$. The objective of this study was to model the combined effects of temperature and moisture content on $\mathrm{CO}_{2}$ and $\mathrm{CH}_{4}$ gas fluxes from drying fresh dairy manure over a $15 \mathrm{~d}$ period.

\section{Materials and methods}

\subsection{Experimental setup and sampling}

Fresh dairy manure was collected from ten lactating dairy cows at the Utah State University Caine Dairy Teaching and Research Center, Wellsville, Utah, USA. After homogenization of the collected samples, about $1 \mathrm{~kg}$ of manure was placed into each of 17 PVC cylinders, $203 \mathrm{~mm}$ in diameter and $38 \mathrm{~mm}$ deep, for ambient drying inside a research greenhouse. The temperature inside the greenhouse was maintained between 5 and $35^{\circ} \mathrm{C}$, and fluctuated with outdoor weather conditions. Two of the 17 cylinders were placed under automated closed dynamic chambers (LI-8100-101, LI-COR Biosciences, Lincoln, NE, USA) that were connected to a portable Fourier transformed infrared (FTIR) analyzer (DX-4030, Gasmet Technology Oy, Helsinki, Finland) for continuous measurement of $\mathrm{CO}_{2}$ and $\mathrm{CH}_{4}$ concentrations for flux estimation $(F)$. Air temperature $\left(T_{\mathrm{a}}\right)$ and manure moisture content were measured with thermal resistance (PT1000, Thermometrics Corporation, Northridge, CA, USA) and electromagnetic (GS3, Decagon Devices Inc., Pullman, WA, USA) sensors, respectively. The GS3 sensor was embedded in the manure to measure continuous changes in temperature $(T)$ and moisture content. The remaining 15 cylinders were placed on a table and prepared for destructive sampling and periodic chemical analyses.

A preliminary study of gas emissions from fresh manure revealed that $\mathrm{CH}_{4}$ emissions fell below detection level within two weeks ${ }^{[7]}$. This subsequent experiment was conducted from January 4 to 19,2013 , over a $15 \mathrm{~d}$ period. In the beginning of the experiment, a homogenized manure sample was analyzed for initial moisture content and chemical composition. After 3, 6, 9, 12 and $15 \mathrm{~d}$, triplicate samples were collected from below the crust of three manure samples to repeat laboratory analyses.

\subsection{Laboratory analyses}

The following parameters were analyzed for each manure sample using methods recommended by Peters et al. ${ }^{[17]}$, (1) wet manure moisture content $\left(M_{C}\right.$, the mass of water relative to total wet mass, $\left.\mathrm{g} \cdot \mathrm{g}^{-1}\right),(2)$ total carbon (TC), (3) dissolved organic carbon (DOC), and (4) $\mathrm{pH}$.

The $M_{C}$ was monitored every 5 min using a capacitance sensor (GS3) that was calibrated based on measurements on oven-dry manure $\left(70^{\circ} \mathrm{C}\right.$ for $\left.24 \mathrm{~h}\right)$. The TC was analyzed on finely ground $(<250 \mu \mathrm{m})$ oven-dried samples with a combustion assay (SKALAR Primacs ${ }^{\mathrm{SLC}}$, Skalar Analytical BV, Breda, The Netherlands). For DOC analysis, a $3 \mathrm{~g}$ subsample of manure was mixed with $30 \mathrm{~mL}$ deionized water and agitated for $1 \mathrm{~h}$ at room temperature. The solution was then centrifuged at $5000 \mathrm{r} \cdot \mathrm{min}^{-1}$ for $10 \mathrm{~min}$. The supernatant was filtered with Whatman no. 542 filter paper. The extracts were immediately stored in a freezer at $-20^{\circ} \mathrm{C}$ and thawed prior to measurements with a carbon analyzer (Phoenix 8000, Tekmar-Dohrmann, Cincinnati, $\mathrm{OH}$, USA). The $\mathrm{pH}$ of the manure was measured with a portable $\mathrm{pH}$ meter (Accumet $\mathrm{pH}$ meter model 50, Hudson, MA, USA) in a 1:2 manure-water slurry $\left(5 \mathrm{~cm}^{3}\right.$ of manure with $10 \mathrm{~mL}$ DI water).

\subsection{Gas emission measurements}

Two LI-COR surface chambers were used for monitoring gas fluxes. Gas samples were sequentially drawn from the closed chambers through a valve manifold and directed to the FTIR analyzer. The concentrations of $\mathrm{CO}_{2}$ and $\mathrm{CH}_{4}$ were recorded in $\mu \mathrm{L} \cdot \mathrm{L}^{-1}$ every $10 \mathrm{~s}$. Each chamber was automatically positioned over the manure sample and sealed for 3 min during measurements of gas concentrations, repeating measurements again at 12 min intervals. During the measurements, air was circulated at a rate of $2 \mathrm{~L} \cdot \mathrm{min}^{-1}$ between the closed chamber and the FTIR analyzer and the increase in gas concentration with time was measured. Each 3 min measurement consisted of a $1 \mathrm{~min}$ gas line purge prior to $2 \mathrm{~min}$ of data collection that was followed by a 3 min break. This cycle was repeated between the two chambers every $6 \mathrm{~min}$. The MATLAB function, robustfit, was employed to estimate the gas fluxes from gas concentrations versus time plots. Later the gas flux units were adjusted from $\mu \mathrm{L} \cdot \mathrm{L}^{-1} \cdot \mathrm{s}^{-1}$ to $\mu \mathrm{mol} \cdot \mathrm{m}^{-2} \cdot \mathrm{s}^{-1}$. The gas emission fluxes reported here at $12 \mathrm{~min}$ intervals were averaged using one 3-min flux estimate from each of the two chambers. 


\section{Mathematical model}

\subsection{Effects of temperature and moisture on gas flux}

Husted $^{[18]}$ found that the Arrhenius equation captured gas production affected by temperature reasonably well,

$$
\ln F=-\frac{E_{a}}{R \cdot(273.15+T)}+k
$$

where $F$ denotes the gas emission flux, $E_{\mathrm{a}}$ designates the energy of activation $\left(\mathrm{kJ} \cdot \mathrm{mol}^{-1}\right), R$ is the gas constant $\left(8.314 \mathrm{~J} \cdot \mathrm{mol}^{-1} \cdot \mathrm{K}^{-1}\right), T$ is the manure temperature $\left({ }^{\circ} \mathrm{C}\right)$ and $k$ is an empirical constant. Maag and Vinther ${ }^{[19]}$ found that $E_{\text {a }}$ changes with moisture content. Myers et al. ${ }^{[20]}$ established a second-order polynomial relationship between nitrogen mineralization and soil water content, which is acceptable for general use because it seems to work well for a wide range of soils. Here, a similar relationship was employed to express $E_{\mathrm{a}}$ as a function of moisture content, $M_{C}$ :

$$
E_{a}=B \cdot M_{C}^{2}+C \cdot M_{C}+D
$$

where $B, C$ and $D$ are model parameters. The combined temperature and moisture dependent gas flux relationship may be expressed as:

$$
\ln F=-\frac{B \cdot M_{C}^{2}+C \cdot M_{C}+D}{R \cdot(273.15+T)}+k
$$

or

$$
F=A \cdot \exp \left[-\frac{B \cdot M_{C}^{2}+C \cdot M_{C}+D}{R \cdot(273.15+T)}\right]
$$

where $A=\exp (k)$.

Two thirds of the gas flux estimates were randomly selected for parameterization and the remaining one third were used for validation of Eq. (4) describing the temperature and moisture effects on gas fluxes.

\subsection{Cumulative emissions}

The cumulative gas emission $(E)$ is the time integration of the gas flux. Sommer and Ersbøll ${ }^{[21]}$ fitted the cumulative ammonia loss from manure slurry with the MichaelisMenten equation:

$$
E=\frac{E_{\max } \cdot t}{t+K_{m}}
$$

where $t$ is the time since start of the experiment, $E_{\max }$ is the maximum gas loss when time approaches infinity and $K_{\mathrm{m}}$ is the time when $E=0.5 E_{\max }$. Misselbrook et al. ${ }^{[22]}$ showed that for some cases the projected $E_{\max }$ could not be derived with reasonable accuracy from fitting Eq. (5) to measured data. There should also be a significant difference in gas emissions if the manure is exposed to high evaporative demand (high temperature and low humidity, i.e., higher rate of drying) versus low evaporative demand (lower temperature and higher humidity, i.e., lower rate of drying). In other words, the gas emission rate is a function of the drying rate given as:

$$
F=f_{F}\left(\left|\mathrm{~d} M_{C} / \mathrm{d} t\right|\right)
$$

where $f_{\mathrm{F}}$ is a time-independent function. Integrating both sides of Eq. (6) with respect to time yields

$$
\int_{0}^{t} F=\int_{0}^{t} f_{F}\left(\left|\mathrm{~d} M_{C} / \mathrm{d} t\right|\right)
$$

or equivalently,

$$
E=g_{F}\left(M_{C 0}-M_{C}\right)
$$

where $g_{F}$ is the integral function of $f_{F}$ and $M_{C 0}$ is the initial moisture content.

To extend the applicability of Eq. (5) to various potential shapes of the cumulative emission curve, an exponential factor was introduced. Also, to account for the influence of the drying rate, time was replaced with the decrease in water content $\left(M_{C 0}-M_{C}\right)$ :

$$
E=E_{\max } \frac{\left(M_{C 0}-M_{C}\right)}{\left(M_{C 0}-M_{C}\right)+k_{m} \cdot \exp \left[-\alpha \cdot\left(M_{C 0}-M_{C}\right)\right]}
$$

where $k_{m}$ and $\alpha$ are positive empirical parameters. Equation (9) maintains the advantages of the Michaelis-Menten equation, where when water is lost, $E$ approaches $E_{\text {max }}$. By replacing time, which can go to infinity in Eq. (5) with the decrease in water content $\left(M_{C 0}-M_{C}\right)$, it now approaches a maximum value $\left(M_{C 0}\right)$.

\section{Results and discussion}

After $15 \mathrm{~d}$ of drying, manure $M_{C}$ decreased from 0.85 to $0.63 \mathrm{~g} \cdot \mathrm{g}^{-1}$ (Fig. 1a). Diurnal changes of manure temperature during the $15 \mathrm{~d}$ drying process are depicted in Fig. $1 \mathrm{~b}$. The manure temperature fluctuated with solar radiation and air temperature inside the greenhouse.

Figure 1c and 1d depict fluxes of $\mathrm{CO}_{2}$ and $\mathrm{CH}_{4}$ as a function of time and temperature. Over the first $3 \mathrm{~d}$ of the drying experiment there was little $\mathrm{CO}_{2}$ and $\mathrm{CH}_{4}$ emitted from the manure. The likely causes for these reduced initial emissions include reduced temperature resulting in inhibited microbial activity ${ }^{[12]}$. The apparent $M_{C}$ of manure was above $0.84 \mathrm{~g} \cdot \mathrm{g}^{-1}$ during the first $3 \mathrm{~d}$, which also likely reduced gas $\left(\mathrm{O}_{2}\right)$ diffusion due to the low amount of air-filled pore space (i.e., too wet). From days 3 to 6 , the emissions of $\mathrm{CO}_{2}$ and $\mathrm{CH}_{4}$ increased with the decline in $M_{C}$. Then $\mathrm{CO}_{2}$ emissions remained at a high rate following diurnal temperature fluctuations, while the $\mathrm{CH}_{4}$ flux gradually decreased until it ceased.

The parameter estimates for gas emission surface plots of $\mathrm{CO}_{2}$ and $\mathrm{CH}_{4}$, with their respective temperature and 
(a)

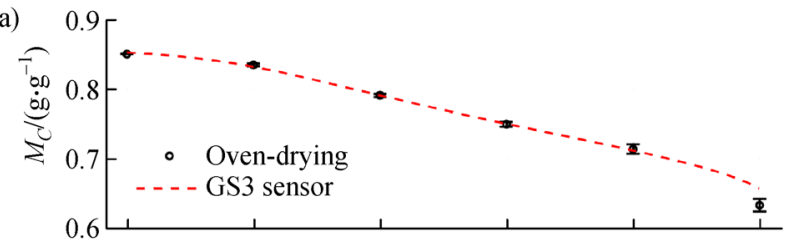

(b)

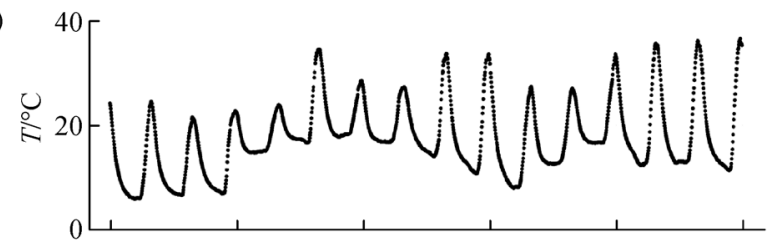

(c)

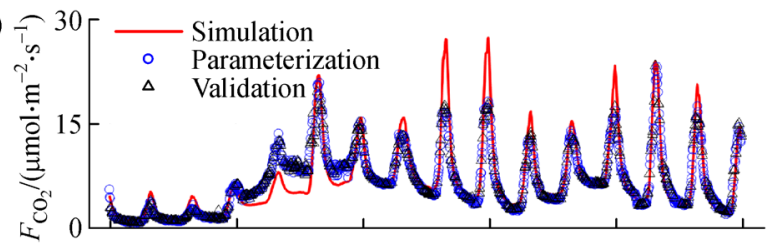

(d)

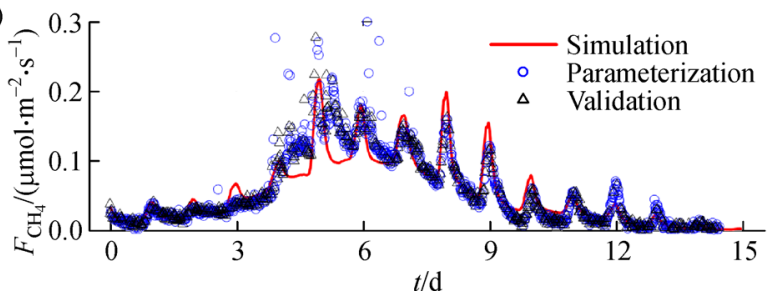

Fig. 1 Sensor-based and gravimetric measurements of wet manure moisture content $\left(M_{C}\right)$ (a), temperature $(T)(b)$, fluxes of $\mathrm{CO}_{2}$ (c) and $\mathrm{CH}_{4}$ (d) during the ambient drying process of dairy manure

moisture dependence are shown in Fig. 2a-2b, respectively. The model validation conducted over $15 \mathrm{~d}$ resulted in high regression correlation coefficients for $\mathrm{CO}_{2}\left(R^{2}=\right.$ $0.862, \mathrm{MSE}=2.05)$ and $\mathrm{CH}_{4}\left(R^{2}=0.717, \mathrm{MSE}=0.034\right)$. Determined regression parameters were $A=3.53 \times 10^{11}$, $B=2.58 \times 10^{5}, C=-3.87 \times 10^{5}, D=2.05 \times 10^{5}$ for $\mathrm{CO}_{2}$ and $A=1.09 \times 10^{6}, B=8.24 \times 10^{5}, C=-1.30 \times 10^{6}, D=$ $5.49 \times 10^{5}$ for $\mathrm{CH}_{4}$.

Neglecting the influence of temperature, the parabolic profiles illustrated in Fig. 2a-2b, reaches peak values when $M_{C}$ is 0.75 and $0.79 \mathrm{~g} \cdot \mathrm{g}^{-1}$ for $\mathrm{CO}_{2}$ and $\mathrm{CH}_{4}$, respectively. This peak is expected considering the competing processes of moisture dependent supply of nutrients, which diminishes with reducing water content and oxygen supply, and gas exchange, which increases with reducing water content. In other words, the reduced emissions at higher $M_{C}$ are associated with reduced gas diffusion through manure with a low number of air-filled pores and the reduction in gas emissions beyond the $M_{C}$ associated with peak gas emissions results from diminishing resources and mobility. The mechanism for reduced pathways for transport of nutrients and movement of microbes is generally a reduction in cross-sectional area for water transport, resulting in reduced microbial activity ${ }^{[15]}$.

The net cumulative losses of $\mathrm{CO}_{2}$ and $\mathrm{CH}_{4}$ from the (a)

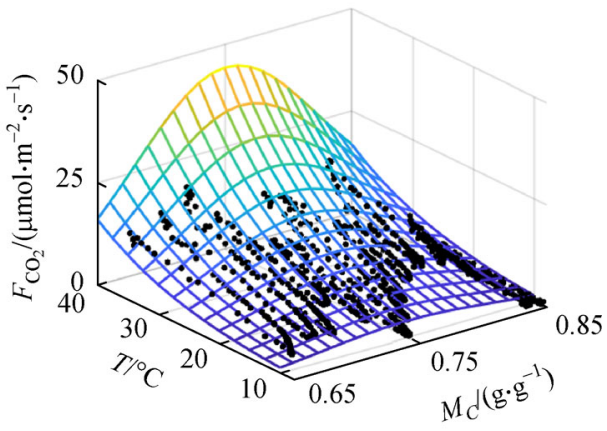

(b)

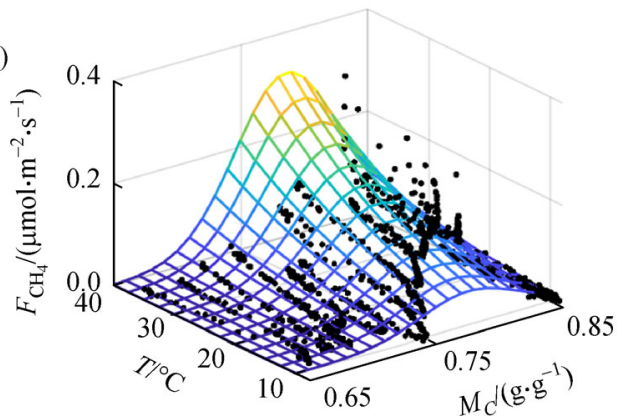

Fig. 2 Two-dimensional fitted surface describing the temperature and moisture dependence of $\mathrm{CO}_{2}$ (a) and $\mathrm{CH}_{4}$ (b) gas fluxes from dairy manure

ambient drying process of manure were calculated by integrating the area beneath each gas flux curve (Fig. 1c and $1 \mathrm{~d}$ ) over the total monitoring period (Fig. 3) as used to fit the cumulative flux data of $\mathrm{CO}_{2}$ and $\mathrm{CH}_{4}$ versus the loss of moisture content in Fig. 3 using parameters of $E_{\max }=$ $10.3 \mathrm{~mol} \cdot \mathrm{m}^{-2}, k_{m}=0.373, \alpha=11.43$ for $\mathrm{CO}_{2}$; and $E_{\max }=$

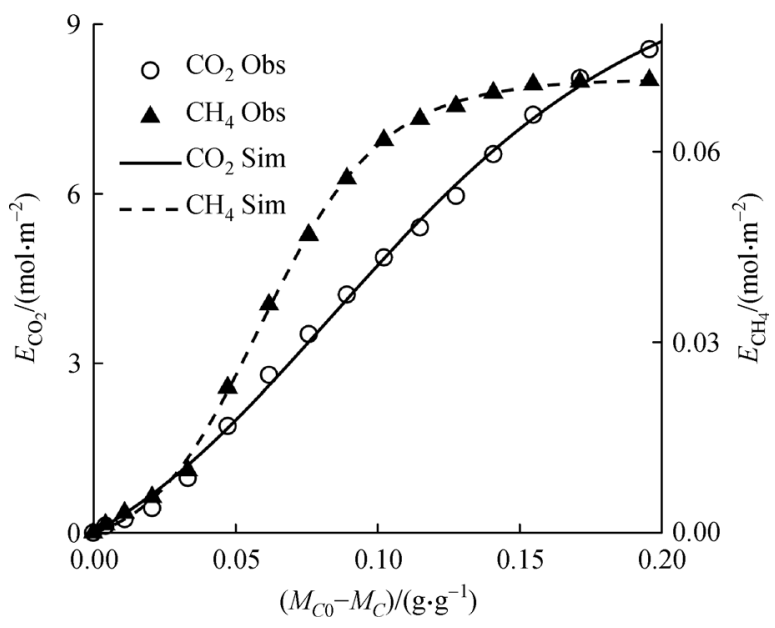

Fig. 3 Cumulative losses of $\mathrm{CO}_{2}$ and $\mathrm{CH}_{4}$ as a function of decreasing moisture content during the drying process of dairy manure. Differences were computed based on the initial moisture content, $M_{C 0}$, as reference. Equation (9) fitted $E_{\max }$ values for $\mathrm{CO}_{2}$ $\left(10.3 \mathrm{~mol} \cdot \mathrm{m}^{-2}\right)$ and $\mathrm{CH}_{4}\left(0.0713 \mathrm{~mol} \cdot \mathrm{m}^{-2}\right)$ represent an estimate of the total gas loss over the manure drying process (i.e., beyond $15 \mathrm{~d})$. 
$0.0713 \mathrm{~mol} \cdot \mathrm{m}^{-2}, k_{m}=0.527, \alpha=34.2$ for $\mathrm{CH}_{4}$. The resulting coefficients of determination exhibited high correlation with $R^{2}$ values of 0.998 for $\mathrm{CO}_{2}$ and 0.999 for $\mathrm{CH}_{4}$, respectively.

At the beginning of the experiment, there was an average of $1038 \mathrm{~g}$ of fresh manure in each cylinder. The initial average moisture content was $85.0 \%$ and the initial TC content was $37.8 \%$, yielding an average total $\mathrm{C}$ mass of $58.9 \mathrm{~g}$ in each cylinder. With the surface area of each cylindrical manure sample of $3.24 \times 10^{-2} \mathrm{~m}^{2}$ and the estimated $E_{\max }$ value from Fig. 3 , the predicted maximum cumulative emission of $\mathrm{CO}_{2}$ would be $4.02 \mathrm{~g} \mathrm{C}$, which represents about $6.83 \%$ of the total $\mathrm{C}$ present in the manure from the beginning of the experiment. This value was slightly lower than the percentage of total C $(9.76 \%)$ reported by Moral et al. ${ }^{[23]}$ for a $52 \mathrm{~d}$ storage of farm yard manure. Similarly, the predicted maximum cumulative $\mathrm{CH}_{4}$ emission was $0.028 \mathrm{~g} \mathrm{C}$, which accounts for $0.047 \%$ of the total initial $\mathrm{C}$ content. The cumulative emission of $\mathrm{CH}_{4}$ here approached the results $(0.06 \%)$ reported by Yamulki ${ }^{[24]}$, but was much lower than other literature values that range from $0.6 \%$ to $9.7 \%{ }^{[23,25]}$. Total $\mathrm{C}$ loss as $\mathrm{CO}_{2}$ and $\mathrm{CH}_{4}(6.88 \%)$ was much higher than the TC decrease shown in Fig. 5 because the cumulative $\mathrm{CO}_{2}$ emission estimated using $E_{\max }$ extends beyond the $15 \mathrm{~d}$ drying process to complete drying (Fig. 3). With the help of the present model, it is feasible to estimate the total $\mathrm{C}$ loss within a relatively short experimental period.

The $\mathrm{pH}$ value of the manure decreased from 7.25 to 6.77 within the first $3 \mathrm{~d}$, then increased slightly over the following $6 \mathrm{~d}$ and rose rapidly from 6.93 to 7.61 over the last $6 \mathrm{~d}$ (Fig. 4). Figure 5 illustrates changes in DOC, TC and DOC/TC during the ambient drying process. The DOC content increased initially and reached the peak concentration $\left(48.9 \mathrm{mg} \cdot \mathrm{g}^{-1}\right)$ on day 6 , then it dropped almost linearly to $32.5 \mathrm{mg} \cdot \mathrm{g}^{-1}$ measured at the end of the experiment. As the labile organic carbon source is most likely directly utilized by microorganisms, DOC accounts for only a small portion of TC (13.9\% at the peak point). The DOC/

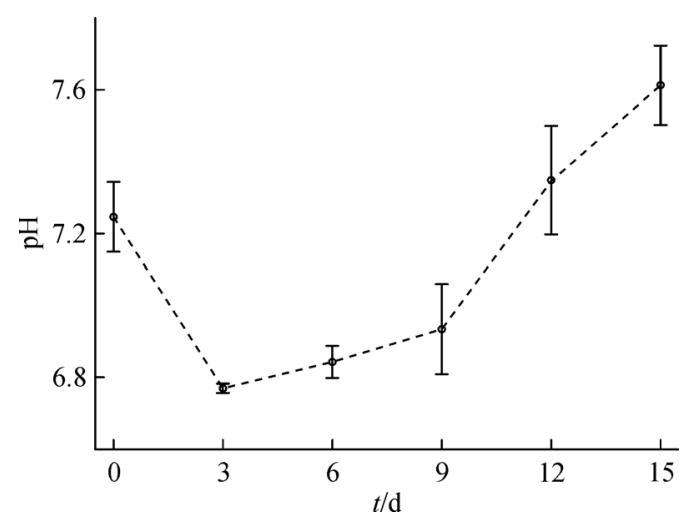

Fig. 4 Changes in $\mathrm{pH}$ during the ambient drying process of dairy manure

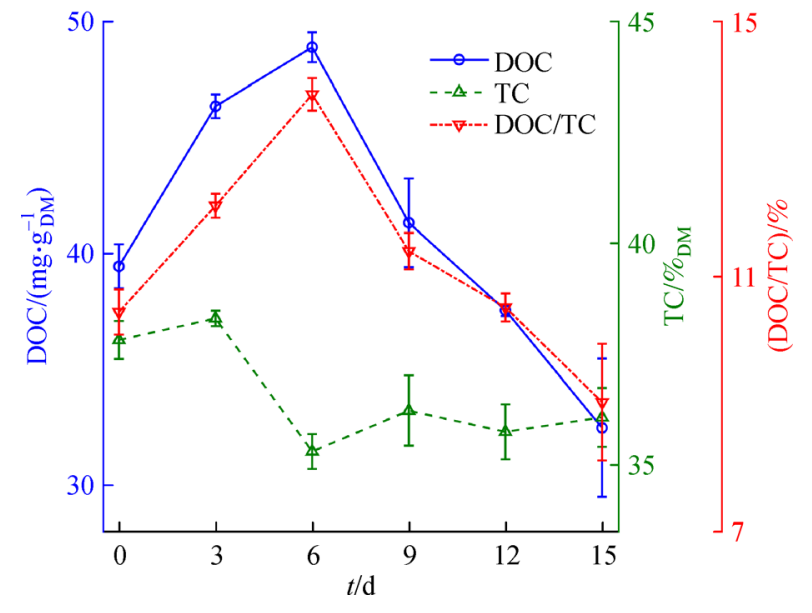

Fig. 5 Changes of DOC, TC and DOC/TC during the ambient drying process of dairy manure. The subscript DM refers to dry matter.

TC ratio follows the same pattern as DOC concentration because the variable range of $\mathrm{TC}$ is relatively small. However, there is a slight decline in TC concentration after day 3 ; then the concentration was relatively low but stable.

The microbial decomposition of organic matter in the manure occurs in two phases ${ }^{[26]}$. First, some of the high molecular weight (MW) organic material is degraded to low MW constituents, such as alcohols and organic acids. Then the low MW organic compounds are degraded to $\mathrm{CO}_{2}$ and $\mathrm{CH}_{4}$ by microbes. In the beginning of the ambient drying process, manure was nearly saturated with an $M_{C}$ of $0.85 \mathrm{~g} \cdot \mathrm{g}^{-1}$, which impeded gas (i.e., $\mathrm{O}_{2}$ ) diffusion and hence respiration activity. Over the first $3 \mathrm{~d}$ of the experiment the production rates of low MW organic compounds were higher than their consumption rates. The TC content was maintained, while the DOC concentration rose gradually. Anaerobic reactions would have been dominant during this stage. The accumulation of organic acids reduced the $\mathrm{pH}$ value to acidic conditions. With continued drying, from days 3 to 6 , much more of the low MW organic components were decomposed because $M_{C}$ decreased and temperature increased. $\mathrm{CH}_{4}$ was generated under anaerobic conditions, while most of the $\mathrm{CO}_{2}$ was produced aerobically. Emissions of $\mathrm{CO}_{2}$ and $\mathrm{CH}_{4}$ showed that the aerobic and anaerobic processes were almost equally important during this stage. However, the reaction rates of the first process were still greater than that of the second. Thus, the content of DOC was still increasing at a slower rate while the TC content slightly decreased. With $\mathrm{CO}_{2}$ and $\mathrm{CH}_{4}$ emissions, some organic acids were degraded and $\mathrm{pH}$ was slightly increased. Beginning with day 6 until the end of the experiment, most of the high MW organic compounds, which are easier to decompose, were degraded into low MW compounds. With increase in the number of air-filled pores, aerobic reaction rates increased while anaerobic activity decreased and finally ceased. 
Aerobic reactions capitalized on this condition consuming abundant DOC. This caused $\mathrm{pH}$ to increase to 7.61 by day 15.

\section{Conclusions}

Gaseous emissions from drying manure are highly dependent on its temperature and moisture content. An empirical surface model derived from the Arrhenius equation was employed to simulate effects of temperature and moisture content on gas fluxes, resulting in excellent agreement with measured $\mathrm{CO}_{2}$ and $\mathrm{CH}_{4}$ emissions. The system of equations provides a new, quantitative and more robust tool for characterizing gaseous emissions from drying manure. Ignoring the effect of temperature, the emissions of $\mathrm{CO}_{2}$ and $\mathrm{CH}_{4}$ peaked at moisture contents of about 0.75 and $0.79 \mathrm{~g} \cdot \mathrm{g}^{-1}$, respectively. The $\mathrm{CH}_{4}-\mathrm{C}$ emission during ambient drying of manure was $0.047 \%$ of the initial $\mathrm{C}$ content. It was mainly generated during the first $10 \mathrm{~d}$. The projected $\mathrm{C}$ losses from $\mathrm{CO}_{2}$ represented $6.83 \%$ of the total initial $\mathrm{C}$ content. Expansion and universal application of this model to estimate gas emissions from a variety of manure sources across the range of temperature and water content experienced for agricultural applications requires implementation of additional physical, chemical and biological factors, which is part of ongoing research.

Acknowledgements The authors are grateful to Bill Mace, Ricardo Tejeda, Jean Almonte and Franyel Silfa for their assistance with technical, hardware and software aspects of this work. This research was supported by funds from the USDA-NIFA AFRI Air Quality Program (2010-85112-50524), the Utah Agricultural Experiment Station, Utah State University, Logan, Utah, USA (approved as journal paper no. 8647), the National Natural Science Foundation of China (41401225), the Fundamental Research Funds for the Central Universities, China (N150204005) and the Natural Science Foundation of Liaoning Province, China (201602250).

Compliance with ethics guidelines Enzhu $\mathrm{Hu}$, Pakorn Sutitarnnontr, Markus Tuller, and Scott B. Jones declare that they have no conflicts of interest or financial conflicts to disclose.

All applicable institutional and national guidelines for the care and use of animals were followed.

\section{References}

1. Liebrand C B, Ling K C. Cooperative approaches for implementation of dairy manure digesters. Washington DC: United States Department of Agriculture (USDA), 2009, 28

2. Leytem A B, Dungan R S, Bjorneberg D L, Koehn A C. Emissions of ammonia, methane, carbon dioxide, and nitrous oxide from dairy cattle housing and manure management systems. Journal of Environmental Quality, 2011, 40(5): 1383-1394

3. Maurer D L, Koziel J A, Bruning K. Field scale measurement of greenhouse gas emissions from land applied swine manure. Frontiers of Environmental Science \& Engineering, 2017, 11(3): 1
4. Owen J J, Silver W L. Greenhouse gas emissions from dairy manure management: a review of field-based studies. Global Change Biology, 2015, 21(2): 550-565

5. Hu E, Babcock E L, Bialkowski S E, Jones S B, Tuller M. Methods and techniques for measuring gas emissions from agricultural and animal feeding operations. Critical Reviews in Analytical Chemistry, 2014, 44(3): 200-219

6. Luo G J, Kiese R, Wolf B, Butterbach-Bahl K. Effects of soil temperature and moisture on methane uptake and nitrous oxide emissions across three different ecosystem types. Biogeosciences, 2013, 10(5): 3205-3219

7. Sutitarnnontr P, Tuller M, Miller R, Jones S B. Monitoring temporal variations in greenhouse and regulated gas emissions from cow manure in relation to moisture content and temperature. In: ASA, CSSA, and SSSA Annual Meeting. Cincinnati, OH, USA, 2012, 1

8. Dewes T. Effect of $\mathrm{pH}$, temperature, amount of litter and storage density on ammonia emissions from stable manure. Journal of Agricultural Science, 1996, 127(04): 501-509

9. González-Avalos E, Ruiz-Suárez L G. Methane emission factors from cattle manure in Mexico. Bioresource Technology, 2001, 80 (1): $63-71$

10. Mazzetto A M, Barneze A S, Feigl B J, Van Groenigen J W, Oenema $\mathrm{O}$, Cerri $\mathrm{C} \mathrm{C}$. Temperature and moisture affect methane and nitrous oxide emission from bovine manure patches in tropical conditions. Soil Biology \& Biochemistry, 2014, 76: 242-248

11. Husted S. Seasonal variation in methane emission from stored slurry and solid manures. Journal of Environmental Quality, 1994, 23(3): 585-592

12. Miller D N, Berry E D. Cattle feedlot soil moisture and manure content: I. Impacts on greenhouse gases, odor compounds, nitrogen losses, and dust. Journal of Environmental Quality, 2005, 34(2): 644-655

13. Tamura T, Osada T. Effect of moisture control in pile-type composting of dairy manure by adding wheat straw on greenhouse gas emission. International Congress Series, 2006, 1293: 311-314

14. Vidal-Beaudet L, Charpentier S. Percolation theory and hydrodynamics of soil-peat mixtures. Soil Science Society of America Journal, 2000, 64(3): 827-835

15. Long T, Or D. Aquatic habitats and diffusion constraints affecting microbial coexistence in unsaturated porous media. Water Resources Research, 2005, 41(8): W08408

16. Sutitarnnontr P, Hu E, Tuller M, Jones S B. Physical and thermal characteristics of dairy cattle manure. Journal of Environmental Quality, 2014, 43(6): 2115-2129

17. Peters J, Combs S M, Hoskins B, Jarman J, Kovar J L, Watson M E, Wolf A M, Wolf N. Recommended methods of manure analysis. Madison, WI, USA: Cooperative Extension Publishing Operations, University of Wisconsin-Extension, 2003

18. Husted S. An open chamber technique for determination of methane emission from stored livestock manure. Atmospheric Environment. Part A, General Topics, 1993, 27(11): 1635-1642

19. Maag M, Vinther F P. Nitrous oxide emission by nitrification and denitrification in different soil types and at different soil moisture contents and temperatures. Applied Soil Ecology, 1996, 4(1): 5-14

20. Myers R J K, Campbell C A, Weier K L. Quantitative relationship between net nitrogen mineralization and moisture content of soils. 
Canadian Journal of Soil Science, 1982, 62(1): 111-124

21. Sommer S G, Ersbøll A K. Soil tillage effects on ammonia volatilization from surface-applied or injected animal slurry. Journal of Environmental Quality, 1994, 23(3): 493-498

22. Misselbrook T H, Powell J M, Broderick G A, Grabber J H. Dietary manipulation in dairy cattle: laboratory experiments to assess the influence on ammonia emissions. Journal of Dairy Science, 2005, 88(5): 1765-1777

23. Moral R, Bustamante M A, Chadwick D R, Camp V, Misselbrook T $\mathrm{H}$ N. N and C transformations in stored cattle farmyard manure, including direct estimates of $\mathrm{N} 2$ emission. Resources, Conservation and Recycling, 2012, 63: 35-42
24. Yamulki S. Effect of straw addition on nitrous oxide and methane emissions from stored farmyard manures. Agriculture, Ecosystems \& Environment, 2006, 112(2-3): 140-145

25. Chadwick D R. Emissions of ammonia, nitrous oxide and methane from cattle manure heaps: effect of compaction and covering. Atmospheric Environment, 2005, 39(4): 787-799

26. Ahring B K. Perspectives for anaerobic digestion. In: Biomethanation I, Ahring B K, Angelidaki I, Conway de Macario E, Gavala H N, Hofman-Bang J, Macario A J L, Elferink S J W H O, Raskin L, Stams A J M, Westermann P, Zheng D, Editors. Berlin, Heidelberg, New York, Hong Kong, London, Milan, Paris, Tokyo: Springer, 2003, 220 